\title{
Leadership: The Effect of Gender on the Openness in Experience and on the Practices of Educational Leadership in Differentiated Teaching
}

\author{
Athanasia Gaitanidou (Corresponding author) \\ $\mathrm{PhD}$, Director of Education Kavala Prefecture, Greece \\ Tel: 030-2510-291572. \\ E-mail: athanagaitan@gmail.com; agaitani@phyed.duth.gr \\ Vassiliki Derri \\ Professor of SPESS, School of Physical Education and Sport Science, \\ Democritus University of Thrace, Greece \\ E-mail: vaderri@phyed.duth.gr \\ Athanasios Laios \\ Professor of SPESS, School of Physical Education and Sport Science, \\ Democritus University of Thrace, Greece \\ E-mail: alaios@phyed.duth.gr \\ Evangelos Bebetsos \\ Professor of SPESS, School of Physical Education and Sport Science, \\ Democritus University of Thrace, Greece \\ E-mail: empempet@phyed.duth.gr \\ Fotios Kalfopoulos \\ Primary School teacher, Master of Arts, Greece \\ E-mail: kalfotis92@gmail.com
}

Received: October 1, 2019

doi:10.5296/jet.v7i1.15836
Accepted: October 25, 2019 Published: November 15, 2019

URL: http://dx.doi.org/10.5296/jet.v7i1.15836

\begin{abstract}
In last decades researches have been undertaken on educational leadership and the linking of the various leadership models with the improvement of school units. Leader's characteristics are an important factor in the leadership's interpretation. The aim of the present study was to look for possible differences in the behaviors of the educational leadership: (a) differentiated
\end{abstract}


teaching on the kinesthetic type of intelligence and the cross-thematic content, (b) the personality trait, the openness in experience of male and female principals, and (c) assess the impact of personality traits, receptivity to experience, behaviors of educational leadership in diversified teaching with regard to the kinesthetic type of intelligence and the cross-thematic teaching content. The survey involved 194 principals from all regions of Greece. The quantitative analysis of the data confirmed the practice of teaching practices in differentiated teaching on the kinesthetic type of intelligence and the cross-thematic content by women to a greater extent but not statistically significant. Differences between the male and female principals were statistically significant in the personality trait "Openness in experience" in favor of women. The "Openness in experience" feature interpreted $12.3 \%$ of the "Instructional leadership in kinetic cross-thematic approaches", F (1, 192) = 26.909, p <0.001. This study is of great importance for the selection and training of primary school unit principals in guiding differentiated teaching, in terms of learning profile and cross-thematic content.

Keywords: Gender, Openness in Experience, Educational Leadership, Differentiated Teaching

\section{Introduction}

Since the 1970s, surveys have strengthened the position of the school by presenting as a key educational factor the achievement of students by strong leadership by defining direction (Weber, 1971; Edmonds, 1979). Instructional leadership is the most established concept that links leadership to learning as leadership focuses on defining school direction, teacher behavior, and aims at teaching learners through teacher education (Bush \& Glover, 2014; Hallinger \& Heck, 2010). The orientated approach adopted in Northern Ireland (2004) was the unified nature of knowledge in the content of the curriculum (Greenwood, 2013), while in the USA the modern reform efforts emphasized the need for links between the thematic areas (Czerniak, 2007; Parker, Heywood, \& Jolley, 2011). Similarly, in Greece, the Cross-curricular Framework Program of Studies (DEPP), which attempted a horizontal cross-linking of the courses through fundamental transatlantic concepts, aimed at changing the objectives and the teaching methodology (Alachiotis, 2002). The application of kinetic cross-thematic programs is proposed because it differentiates the teaching of the learner's learning profile and promotes active learning in many scientific fields. It develops skills that are transferred to new conditions, enhances the learning of basic abstract concepts and critical thinking (Kaittani, Kouli, Derri, \& Kioumourtzoglou, 2017).

The question posed in the present study is "What characteristics of a school leader can determine the direction, and more specifically, the differentiated teaching in classroom?"

In the international literature, Burns' placement (1978) linked leadership with the ability to achievement and temperament, while Bass highlighted the personality as an important factor in the behaviors of leadership (Bass, 1990). Characteristics such as self-confidence, sociability, adaptability and collaboration are believed to allow leaders to inspire their partners, and to increase the likelihood of leadership efficiency (Spillane, Haverson, \& Diamond, 2004). 
The overview of surveys highlighted a small but statistically significant gender outcome in educational leadership, with more active leadership by female school leaders (Hallinger, Dongyu, \& Wang, 2016).

The current literature lacks data that examine the influence of gender and receptiveness on the experience of principals in the behaviors of educational leadership in differentiated teaching in terms of learning profile that is kinetic cross-thematic approaches to knowledge.

\subsection{Instructional Leadership}

In the twenty-first century, the main direction for the educational administration of the school is international, cultural and intercultural (Dimmock \& Walker, 2000). The international direction has led to increased interest in the phenomenon of globalization of educational policy and practice, creating needs for the development of specialized (Katsaros, 2008) and international education management conditions (Dimmock, 1999; Dimmock \& Walker, 2010). Differences in educational administration stem from the different cultural, national and sociological contexts that shape education in every cultural environment (Hallinger \& Murphy, 1985; Veeriah, Piaw, Li, \& Hoque, 2017). In this way, the cultural contexts influence all the perceptions, values and model attitudes and behaviors of the school leaders who are leaders in each school unit (Dimmock \& Walker, 2013; Hallinger \& Murphy, 1985; Pasiardis, 2004).

Educational leadership models assume that school leaders have both the specialized knowledge and the formal authority to influence teachers. Leadership studies indicate that administration is strongly influenced by the organizational and social context with which the educational organization interacts (Leithwood \& Jantzi, 1999). The educational leadership started as part of the effective school movement of the 1970s for the school's contribution to reducing social inequalities. Over the years, the focus of this approach on leadership has shifted from administration to leadership, personal characteristics of effective leaders, and later to the behavior or behaviors of principals in effective schools (Sun \& Leithwood, 2015).

Determining the school mission, managing the training program, promoting a positive school culture are dimensions of the instructional leadership model (Sun \& Leithwood, 2015).

Sheppard (1996) claimed that there are "broad" and "close" perceptions of educational leadership. More specifically, the broad approach includes school culture with significant implications for teachers' behavior, teachers' commitment, teacher involvement in innovation. The close approach focuses on educational leadership as a separate entity from administration with actions that are directly related to teaching and learning, with observations on teacher's behaviors and classroom supervision. Instructional leadership usually assumes leaders' critical focus on teacher behavior as they are involved in activities that directly affect student development (Bush \& Glover, 2003). The analysis of surveys published from the early 1970s to 2000, studied the impact of educational leadership on students' achievements. Educational leadership has been positively correlated with student achievements (Waters, Marzano, \& McNulty, 2005). 
1.2 Differentiated Teaching on the Kinesthetic Type of Intelligence with the Cross-Thematic Content

Modern child-centeredness approach is the learning process that allows the child to handle and approach genuine interests and concerns, as they arise from the search within the group, in a dialectical relationship between group and individual. The complexity and peculiarity of each student, mainly based on the theories of multiple intelligences, responds to situations that are of particular interest to the children (Chrysafidis, 2011). In the same direction, Placek (1992) states that with the implementation of traditional curricula, all types of intelligence are not developed, since the separation of knowledge into distinct categories makes it difficult for children to link individual cognitive fields to real, authentic situations of life (Placek, 1992).

The cross-thematic approach has the characteristic that it is based on the real interests and team concern (Chrysafidis, 2011). In the methodology of cross-thematic child-centeredness dominates. The student, at all stages of the application of the method, holds the central position (Koptis, 2009).

The cross-thematic is innovation as well as the management of the curriculum with cross-thematic teaching, which differentiated lessons in content that are implemented in the school unit. Three models have been proposed in the international literature to teach the cross-thematic approach: affiliate, public, and collaborative. Kinetic cross-thematic approaches have two forms of internalization (in the field of Physical Education) and externalization with other curricular content such as language, mathematics, natural sciences or social sciences (Placek \& O'Sallivan, 1997).

\subsection{Personality-Theory of the Five Factors}

One of the leading scholars of the leadership, Bass, described leadership as a phenomenon in which exercise personality is an important factor (Bass, 1990). The concept of personality structure refers to the most stable and unchanging aspects of the person (Cervone \& Pervin, 2013). The view found to be consistent with the majority of theoretical features in the last years of the 20th century is that human personality consists of five factors. The theory of five factors supports the five characteristics, extroversion, neuroticism, receptivity to experience, agreeableness and conscientiousness, as a psychological structure that all people have in varying degrees (Cervone \& Pervin, 2013). The present study evaluated the effect of a characteristic of the great five, the receptivity to the experience in the educational leadership in kinetic cross-thematic approaches that is the organization and realization of the kinetic interdisciplinary teaching.

The factor receptivity in the experience evaluates the search for activity, the appreciation of the experience, the tolerance towards the unknown and its investigation (Pervin \& John, 2001). Receptiveness also relates to the tendency to accept the values of other fellow humans (Brookings, Zembar, \& Hochstetler, 2003). The six facets of the personality of the person who are included in the factor of receptivity to experience are: imagination, aesthetics, feelings, ideas, actions, values. The person is characterized as aesthetically sensitive, imaginative, free-minded, intellectual, curious (exploratory), open-minded, innovative, genuine, intelligent. The adjectives and phrases that characterize the person who is not 
receptive to the experience are: Conventional, down-to-earth with limited interest, lacking artistic sensitivity, having difficulty in analytical thinking (Cervone \& Pervin, 2013).

Surveys have shown that individual differences in scores of five factors predict significant outcomes in areas of great importance, such as professional guidance, personality diagnosis, work behavior (Cervone \& Pervin, 2013; Judge, Bono, Ilies, \& Gerhardt, 2002).

\subsection{Gender, Instructional Leadership and Personality Trait Openness}

Hallinger and his colleagues (2016), in a meta-analysis of 28 international surveys with a sample of 2,000 managers from 1983 to 2014, showed a "small but statistically significant outcome" of gender in educational leadership, with more active leadership than female directors (Hallinger, Dongyu, \& Wang, 2016). Gaitanidou's survey (2019) on a sample of 223 primary school teachers in Central Macedonia and Eastern Macedonia and Thrace showed that there were no statistically significant differences between male and female principals in "educational leadership in kinetic interdisciplinary approaches" $(\mathrm{F}=2.835$, Sig $=$ $0.094>0.05)$.

\section{Objectives}

1. To search for possible differences between male and female school unit principal in the practice-behavior of the educational leadership in differentiated teachings on the kinesthetic type of intelligence and the cross-thematic content.

2. To look for potential differences in personality traits, receptivity to the experience of male and female school principals.

3. To examine the impact of receptivity on experience, behavioral practices of educational leadership, differentiated teachings on the kinesthetic type of intelligence and cross-thematic teaching content.

\subsection{Hypotheses}

1. There is a statistically significant difference in the average behaviors of educational leadership in differentiated teaching with kinetic cross-thematic approaches between male and female school unit principals.

2. There is a statistically significant difference in the average personality traits, openness in experience of male and female school principals.

3. There is a statistically significant effect of personality trait, openness in experience, and behaviors of educational leadership in differentiated teaching with kinetic cross-thematic approaches.

\subsection{Materials and Methods}

Sample: One hundred and sixty three principals (118 males and 76 females) from different regions of Greece with administrative experience from 1 to 26 years ( $M=6$ years) participated voluntarily.

Procedure: The questionnaire was distributed via an online form created at 
http://www.google.gr and sent online to school principals. The questionnaires did not collect any information that could harm the mental or social integrity of the participants. They filled it up without mentioning personal email to preserve their anonymity.

\section{Tool}

\subsection{Instructional Leadership Practices in Kinetic Interdisciplinary Approaches}

The practices of the educational leadership in kinetic cross-thematic approaches were evaluated by the Gaitanidou questionnaire (2019), valid and reliable with statistically significant norms X2 (X2/df) = 2,047, GFI = 0,826, AGFI = 0,786, CFI = 0,950, NFI = 0,908, $\mathrm{RMR}=0,053$, RMSEA $=0,069$ in a survey with a sample of 223 principals in Greece. It consists of thirty-one (31) questions and four factors that measure the characteristics and behaviors of the educational leadership in kinetic cross-thematic approaches: Providing Resources, Cross-thematic Teaching with physical education, Guidance of Cross-thematic Teaching, Intense Presence. The answers were given on a graded Lickert-grade 5-grade scale where (1) means the response to the proposal to a minimum, I totally disagree, (2) to a small extent, I disagree (3) to a moderate degree, I am not sure, (4) to a large extent, I agree, and (5) to a very large extent, I totally agree. (e.g. I help educators to develop appropriate practices for differentiated teaching (adaptation to individual needs and learning styles of students).

\subsection{NEO Personality Inventory Revised (NEO-PI-R)}

The personality trait was investigated with the NEO-PI-R questionnaire (Cervone \& Pervin, 2013; Costa, McCrae, \& Dye, 1991; Pervin \& John, 2001). It contains a bunch of twelve (12) questions, with everyday words used to describe the personality trait. Costa and McCrae (1992) (written in Cervone \& Pervin, 2013) report a longitudinal test-over-review of reliability factors, over six years, for experience receptivity ranging from 0.68 to 0.83 . The research findings document the reliability and validity of the questionnaire (Costa, Mccrae, \& Dye, 1991; Goldberg, 1990; Tsaousis \& Kerpelis, 2004). The research tools have been tested for its content and construct validity. The construct validity of the NEO-PI-R instrument was examined and results are satisfactory. However, analytically quoting these results is not the purpose of this study.

\section{Statistical Analysis}

Analysis was made using the SPSS V21 statistical packet. The methodology followed in the analysis of quantitative data refers to methods of descriptive statistics for the numerical description of the sample, averages, standard deviations, frequencies. Independent sample t-test was used to investigate the interaction between the independent variables gender and practices. Instructive Leadership Practices in Kinetic interdisciplinary approaches and features of personality.

Independent sample t-test was used to investigate the interaction between gender independent variables and instructional leadership in kinetic cross-thematic approaches and traits of personality, Openness. A regression analysis was applied to examine the correlation between Instructional Leadership Practices in Kinetic cross-thematic approaches and traits of personality, Openness in experience. 
Table 1. Gender, Mean, SD of the Instructional leadership in kinetic thematic-cross approaches and Openness in experience

\begin{tabular}{lllllll}
\hline Variables & Gender & $\mathrm{N}$ & Mean & $\mathrm{SD}$ & $\mathrm{t}$ & $\mathrm{p}$ \\
\hline \multirow{2}{*}{ Instructional leadership in kinetic thematic-cross approaches } & Males & 118 & 3.7434 & 0.68214 & \multirow{2}{*}{0.558} & 0.129 \\
& Females & 76 & 3.9057 & 0.74742 & & \\
\multirow{2}{*}{ Openness in experience } & Males & 118 & 3.6627 & 0.98561 & \multirow{2}{*}{4,528} & 0.000 \\
& Females & 76 & 4.2368 & 0.62201 & & \\
\hline
\end{tabular}

Female principals seem to have more features of Openness in experience, $t(192)=4,528$, $\mathrm{p}<0.001$ the results showed statistically significant differences between male and female. In the factor "Instructional leadership in kinetic cross-thematic approaches" the results showed the female have more behaviors of transformational leadership, but not statistically significant.

Then, a correlation analysis was made on the receptiveness of experience (personality trait) and Instructional leadership in kinetic cross-thematic approaches to determine their possible relationship. The correlation analysis showed that there is a positive correlation, statistically significant, between the "Openness" feature and the "Instructional leadership in kinetic interdisciplinary approaches" factor with $\mathrm{r}=+0.351$ and Sig. $=0.000<0.01$. Then, to investigate how much dispersion is interpreted in the "Instructional leadership in kinetic cross-thematic approaches" by the "Openness" variable, a reciprocal analysis was performed. The "Openness" feature interpreted $12.3 \%$ of the "Instructional leadership in kinetic interdisciplinary approaches", F $(1,192)=26.909, \mathrm{p}<0.001$. Statistically significant contribution with $(\beta=0.276$, and $\mathrm{t}=5.187, \mathrm{p}<0.05)$.

\section{Discussion}

The purpose of the present study was to determine the possible difference in the average of behaviors of Instructional leadership in kinetic cross-thematic approaches and the dimensions of the receptivity characteristic in the experience between male and female principals. Based on the results, women principals seem to use more of the Instructional leadership in kinetic cross-thematic approaches versus male colleagues in all the factors studied. However, the effect of gender was not significant in all factors of Instructional leadership in kinetic cross-thematic approaches. The international bibliography highlighted more active female leadership (Hallinger, Dongyu, \& Wang, 2016), but did not provide a separate view on whether gender-based leadership style suggests that personality and experience may be the main influences for adopting the behaviors of educational leadership. The literature search has shown that leadership demands leaders who are familiar with the management of administrative processes to improve teaching, are knowledgeable about learning objects, have skills that build trust and problem-solving skills in the school community (Robinson, 2010) without referring to different performance of gender effects.

Also, in the present study the personality trait, the receptiveness to experience, showed differences in the averages between male and female principals. Therefore, female principals are expected to be more receptive to experience, more active, imaginative, free, exploratory, 
aesthetic, and feelings (Pervin \& John, 2001). Receptiveness also relates to the tendency to accept the ideas and values of other fellow humans (Brookings, Zembar, \& Hochstetler, 2003). The present study does not confirm the international research that has shown women tend to have higher rates of neuroticism, extroversion, conscientiousness and agreeability (Costa, Terracciano, \& McCrae, 2001), but not in the receptivity to experience.

The research has highlighted the openness in experience characteristics to positively influence the exercise of educational leadership towards guiding and encouraging teachers to implement activities and teaching extensions by diversifying course contents by overcoming fields in teaching, social skills, accepting diversity among pupils, developing appropriate practices for differentiated teaching (adaptation to individual needs and learning styles of students).

In particular, directors will enrich school life with imagination and aesthetics, "colors and perfumes" that are required for the student's balanced development. The inclusion of students in the laboratory, group and experiential groups will help them develop social skills of acceptance of diversity in order to live as creative citizens in societies with cultural diversity.

\section{Conclusion}

The gender of principals is a differentiation in personality, openness in experience. In particular, females seem to have developed more dimensions of openness in experience. The feature of the personality of openness in experience is a foreseeable factor in the practices of the educational leadership, guided by the differentiated teaching in terms of content (process), process (group, inventive, experiential, creative) in terms of outcome type of intelligence, interests, early knowledge). Taking into account strong leadership as a key educational factor in achieving students and abilities, skills and differences, specially structured criteria can contribute to the selection of competent educational staff as well as training programs that can contribute to the development of their competences and skills of principals to encourage the school principal to encourage kinetic cross-thematic teaching, diversified teaching to content, process, taking into account the kinesthetic type of intelligence.

\section{References}

Alachiotis, S. (2002). For a modern education system. Review of Educational Issues, (7), 7-16.

Bass, B. M. (1990). Handbook of Leadership: Theory, Research and Managerial Applications (3rd ed.). New York: The Free Press.

Brookings, B. J., Zembara, J. M., \& Hochstetler, M. G. (2003). An interpersonal circumplex/five-factor analysis of the Rejection Sensitivity Questionnaire. Personality and Individual Differences, 34, 449-461.

Burns, J. (1978). Leadership. New York: Harper \& Row.

Bush, T., \& Glover, D. (2003). School Leadership: Concepts and Evidence. Nottingham: National College for School Leadership, Spring. 
Bush, T., \& Glover, D. (2014). School leadership models: what do we know? School Leadership \& Management, 34(5), 553-571.

Cervone, D., \& Pervin, L. (2013). Theories of Personality, Research and Applications (2761 ed.). (M. A., Ed., \& K. Alexander Alexandroupou A., Trans.) Athens: Gutenberg.

Chen, W., Cone, P. T., \& Cone, L. S. (2007). A Collaborative Approach to Developing an Interdisciplinary Unit. Journal of Teaching in Physical Education, 26, 103-124.

Chrysafidis, K. (2011). Interdisciplinary approach to knowledge. Athens: Diptych. Appendix.

Costa, P. T. Jr., \& McCrae, R. R. (1992). Revised NEO Personality Inventory (NEO-PI-R) and NEO Five-Factor (NEO-FFI) Inventory professional manual. Odessa, FL: Psychological Assessment Resources.

Costa, P. T. Jr., Mccrae, T. R., David, A., \& Dye, A. D. (1991). Facet Scales For Agreeableness Conscientiousness: A Revision Of NEO Personality Inventory. Person. indicid. Difl, 12(9), 887-898.

Costa, P. T. Jr., Terracciano, A., \& McCrae, R. R. (2001). Gender differences in personality traits across cultures: Robust and surprising findings. Journal of Personality and Social Psychology, 81(2), 322-331.

Czerniak, C. M. (2014). Interdisciplinary science teaching. In S. K. Abell \& N. G. Lederman (Eds.), Handbook of research on science education (pp. 537-559). New York: Routledge.

Dimmock, C. (1999). Principals and school restructuring: Conceptualising challenges. Journal of Educational Administration, 37(5), 441-462.

Dimmock, C., \& Walker, A. (2000). Globalisation and Societal Culture: Redefining schooling and school leadership in the twenty-first century. Compare: A Journal of Comparative and International Education, 30(3), 303-312.

Dimmock, C., \& Walker, A. (2010). Developing Comparative and International Educational Leadership and Management: A crosscultural model. School Leadership \& Management Formerly School Organisation, 20(2), 143-160.

Dimmock, C., \& Walker, A. (2013). Insights into Educational Administration: The Need for a Cross-Cultural Comparative Perspective. Asia Pacific Journal of Education, 20(2), $11-22$.

Edmonds, R. (1979). Effective schools for the urban poor. Educational Leadership, 37(1), $15-27$.

Goldberg, L. R. (1990). An Alternative "Description of Personality": The Big-Five Factor Structure. Journal of Personality and Social Psychology, 59(6), 1216-1229.

Greenwood, R. (2013). Subject-based and cross-curricular approaches within the revised primary curriculum in Northern Ireland: Teachers' concerns and preferred approaches. Education 3-13, 41(4), 443-458. 
Hallinger, P., \& Heck, R. H. (2010). Collaborative leadership and school improvement: Understanding the impact on school capacity and student learning. School Leadership and Management, 30(2), 95-110.

Hallinger, P., \& Murphy, J. (1985). Assessing the Instructional Management Behavior of Principals. The Elementary School Journal, 86(2), 217-247. Retrieved from https://www.jstor.org/stable/1001205?seq=1\#page_scan_tab_contents

Hallinger, P., Dongyu, L., \& Wang, W. C. (2016). Gender Differences in Instructional Leadership: A Meta-Analytic Review of Studies Using the Principal Instructional Management Rating Scale. Educational Administration Quarterly, 52(4), 567-601.

Kaittani, D., Kouli, O., Derri, V., \& Kioumourtzoglou, E. (2017). Interdisciplinary Teaching in Physical. Education, Arab Journal of Nutrition and Exercise, 2(2), 91-101.

Katsaros, I. (2008). Organization and Management of Education. Athens: Pedagogical Institute.

Koptsis, A. (2009). Basic principles of modern Teaching and their application to Project methodology. Educational Issues Review, 15, 16-28.

Leithwood, K., \& Jantzi, D. (1999). Transformational School Leadership Effects: A Replication. School Effectiveness and School Improvement, 10(4), 451-479.

Leithwood, K., Jantzi, D., \& Hopkins, M. C. (2006). The development and testing of a school improvement model. School Effectiveness and School Improvement, 17(4), 441-464.

Parker, J., Heywood, D., \& Jolley, N. (2012). Developing pre-service primary teachers' perceptions of cross-curricular teaching through reflection on learning. Teachers and Teaching Theory and Practice, 18(6), 693-716.

Passiardis, P. (2004). Educational Leadership. Athens: Metaíchmio.

Pervin, L., \& John, O. (2001). Theories of Personality, Research and Applications (No. 120 ed.). (M. Zoi, Ed., \& E. Alexandropoulou A., Trans.) Athens: printed.

Placek, J. H. (1992). Rethinking middle school physical education curriculum: An integrated, thematic approach. Quest, 44(3), 330-341.

Placek, J. H., \& O'sullivan, M. (1997). The many faces of integrated physical education. Journal of Physical Education, Recreation \& Dance, 68(1), 20-24.

Robinson, V. (2010). From Instructional Leadership to Leadership Capabilities: Empirical Findings and Methodological Challenges. Leadership and Policy in Schools, 9(1), 1-26.

Sheppard, B. (1996). Exploring the transformational nature of instructional leadership. Alberta Journal of Educational Research, XLII(4), 325-44.

Spillane, J. P., Haverson, R., \& Diamond, J. B. (2004). Towards a theory of leadership practice: A distributed perspective. Journal of Curriculum Studies, 36(1), 3-34.

Sun, J., \& Leithwood, K. (2015). Direction-setting school leadership practices: A 
meta-analytical review of evidence about their influence. School Effectiveness and School Improvement, 26(4), 499-523.

Tsaousis, I., \& Kerpelis, P. (2004). The Traits Personality Questionnaire 5 (TPQue5), Psychometric Properties of a Shortened Version of a Big Five Measure. European Journal of Psychological Assessment, 20(3), 180-191.

Veeriah, J., Piaw, Y. C., Li, Y. C., \& Hoque, E. K. (2017). Teachers' Perception On The Relationships Between Transformational Leadership And School Culture In Primary Cluster Schools. Malaysian Online Journal of Educational Management, 5(4), 18-34.

Waters, T., Marzano, R. J., \& McNulty, B. (2005). McREL's Balanced Leadership Framework: Developing the Science of Educational Leadership. Journal of research and information for $\mathrm{K}-12$ public educators.

Weber, G. (1971). Inner-city children can be taught to read: Four successful schools. Washington, D.C.: Council for Basic Education, 18, 1-38.

\section{Copyright Disclaimer}

Copyright reserved by the author(s).

This article is an open-access article distributed under the terms and conditions of the Creative Commons Attribution license (http://creativecommons.org/licenses/by/3.0/). 